\title{
Economic Analysis of ART Task Shifting in Limited Resource Setting Using Econometric Model: Ethiopia Case Study
}

\author{
By Elias Asfaw ${ }^{*}$ \\ Naod Mekonnen ${ }^{\dagger}$ \\ Benjamin Johns \\ Wendy Wong ${ }^{+}$ \\ Abebe Bekele \\ John G H Palen" \\ Amha Kebede \\ Sarah Dominis" \\ Yibeltal Assefa"
}

The present study attempts to estimate cost differences associated with anti-retroviral therapy (ART) task shifting in a limited resource setting in Ethiopia, and to analyze the determinant factors for length and cost of a visit. A stratified random sample of health facilities was surveyed. An ordinary least square (OLS) regression model was employed. The average time spent by patients in ART services was estimated to be 8.5 minutes (Range: 1 to 60 minutes). The OLS model estimated that the median cost per visit for doctors was $15 \%$ higher than for the nurses, when controlling for type of facility and type of visit. We found that ART services were less costly when delivered by nurses and health officers, compared with doctors. Since task-shifting to less specialized health-care workers yields additional economic benefits, the expansion of ART task-shifting should be considered by healthcare policy makers and stakeholders in a limited resource settings.

Keywords: Antiretroviral therapy, Econometric model, Ethiopia, Task shifting, Visit cost.

\section{Introduction}

Sub-Saharan Africa is facing a crisis in human health resources, with a critical shortage of health workers exacerbated by a high burden of disease, brain drain, and low motivation (Zachariah et al. 2009). According to recent World Health Organization (WHO) estimates, the current workforce in some of the most affected countries in sub-Saharan Africa would need to be scaled up by as much as $140 \%$ to achieve international health development targets, such as those in the Millennium Declaration (Kinfu et al. 2009, UNAIDS 2013). The

${ }^{*}$ PhD Candidate in Health Economics, University of KwaZulu-Natal, South Africa.

$\dagger$ Researcher, Ethiopian Economics Association, Ethiopian Economic Policy Research Institute (EEA/ EEPRI), Ethiopia.

\$Senior Scientist, Abt Associates, Inc., USA.

${ }^{+}$Scientist, Abt Associates, Inc., USA.

Director, Health System Research Directorate, Ethiopian Public Health Institute (EPHI), Ethiopia.

- Office of Global AIDS Coordinator, US State Department, USA.

• Director, Ethiopian Public Health Institute (EPHI), Ethiopia.

" Senior Scientist, Abt Associates, Inc., USA.

- Director, Research and Technology Transfer, Ethiopian Public Health Institute (EPHI), Ethiopia. 
problem is so serious that in some instances there is no sufficient human capacity to absorb, deploy, and efficiently use the additional funds that are considered necessary to improve health in these countries.

In particular, the burden of HIV/AIDS has led to task shifting - the name now given to a process of delegation whereby tasks are moved, where appropriate, to non-physicians (WHO 2007) as a way of expanding human resource capacity. For example, providing antiretroviral therapy to 1,000 people in settings in which resources are constrained requires an estimated one or two doctors, up to seven nurses, and about three pharmacy staff as well as support from community workers (WHO 2007). The World Health Organization has promoted a "public health" approach to scaling-up ART, and many countries have adopted a standardized ART treatment protocol in which services can be provided by non-physician clinicians, i.e., clinical officers or nurses, moving away from the physician-managed, conventional model of treatment (Charles et al. 2006). In terms of the public health approach, nurse or clinical officer-led ART treatment has emerged in the HIV programs of many developing countries at decentralized levels of care (Harries et al. 2006) as tasks are shifted from physicians to non-physician clinicians, such as nurses, through in-service training and/or training of new cadres.

In Ethiopia, the ART delivery model has shifted from a physician-led, hospital-based program to decentralized service delivery at health centers by nurses and health officers. This strategy contributed to the radical expansion of ART providing facilities from three in $2004 / 5$ to 743 in 2010/11, with ART service recipients increasing from 8276 in $2004 / 5$ to 247805 in $2010 / 11^{1}$. The accelerated expansion of health facilities within short time period has enabled to provide easy service accessibility for the intended target groups, and this in turn enabled the country to move towards universal health coverage. This was the result of the government and other stakeholders' commitment to expanding services for all the people in need. However, there is little information on the cost of visits, cost differences associated with task shifting, decentralization and the determinants for such differences. The length of visit and type of health professional providing these services affect the magnitude of the cost difference. This research seeks to fill this information gap in the literature.

\section{Objective}

Previous studies in Sub-Saharan Africa countries, including Ethiopia, have reviewed the relationship between task performance, access and task shifting (Gessessew et al. 2011, O'Malley et al. 2014), however, there is limited knowledge on the economic significance associated with ART task shifting for policy makers. More importantly, there is a paucity of evidence on the application of micro-econometric modeling to ART task-shifting. This research study examines the relationship between the length of a visit and the labor cost

${ }^{1}$ See: FHAPCO 2012, National AIDS Resource Center. Monthly ART Updates: http://goo.gl/ f38bgA. [Accessed: 10 June 2014] 
of that visit, using the explanatory variables of the healthcare profession types (doctors, health officers and nurses), type of health facilities (hospitals, health centers) and purpose of the visit (initiation, follow-up). We seek to assess if there is a relationship between the health profession type and the type of health facility and both the length and cost of a visit, while controlling for other factors.

\section{Materials and Methods}

A stratified random sample of health facilities across four regions of Ethiopia (Addis Ababa, Amhara, Benishangul Gumuz, and Oromia) was used for the study. The unit of randomization was the health network, consisting of one hospital and its associated health centers. A health network was sampled with certainty if regional staff reported that a physician was involved in ART care at the hospital. A total of 4 health networks were sampled in the survey regions. The hospital and two or three health centers were selected for each health network, out of an average of 5.7 (range 2-15) health centers per network.

As shown in Table 1, with each sampled networks, health facilities were selected. The anchor hospital was selected within each network with certainty together with a sample of 2 or 3 satellite health centers. Only health centers that had been delivering ART as of the end of 2010 were included in the sampling framework. If there were fewer than 4 eligible health centers in the network, then all facilities will be selected. For networks with 4 or more eligible health centers, further stratifications of the health centers were performed into those with a longer history of delivering ART service and those newer to ART service delivery. At the first instance, one clinic was selected from the first stratum. Then, secondly two additional clinics were randomly selected from the second stratum, and the balance from the first stratum. Substitution was used for nonresponse due to inaccessibility. This only occurred once. In this instance, the weight of originally selected clinic was simply given to its replacement. Finally, at the surveyed health facilities where data on costs were collected, exit interviews with clients were performed. Patients attending their antiretroviral treatment, at the surveyed health facilities, were interviewed. Consecutive sample of 15 adult patients $(>18$ years) per a course of a day per facility were interviewed and relevant time motion checklist measured and filled. The cost of resources used to deliver ART service was obtained from the sampled health facilities. Supplemental cost evidence was collected from the Ethiopia Federal Ministry of Health (FMOH) and Pharmaceutical Fund and Supply Agency (PFSA).

All data collectors were given three days of training before the data collection commenced, and were accompanied by senior supervisors who checked the data collection daily. The data collection instruments include health facility manager interview guide, patient record checklist, time-motion checklist and costing sheets. The tools were piloted at one hospital and one health center in Addis Ababa, finalized, and then applied to all health facilities in the analysis. 
Table 1. Sampling Frame and Surveyed Health Facilities

\begin{tabular}{|l|c|c|c|c|}
\hline Region & $\begin{array}{c}\text { Randomly } \\
\text { Sampled } \\
\text { Networks }\end{array}$ & $\begin{array}{c}\text { Networks } \\
\text { selected with } \\
\text { certainty }\end{array}$ & $\begin{array}{c}\text { Total studied } \\
\text { networks }\end{array}$ & $\begin{array}{c}\text { Visited } \\
\text { Facilities }\end{array}$ \\
\hline Addis Ababa & 4 of 6 & 0 & 4 & 15 \\
\hline Amhara & 4 of 12 & 5 & 9 & 32 \\
\hline $\begin{array}{l}\text { Benishangul } \\
\text { Gumuz }\end{array}$ & 0 & 2 & 2 & 8 \\
\hline Oromia & 4 of 28 & 2 & 6 & 24 \\
\hline Total & 12 of 46 & 9 & 21 & $\mathbf{7 9}$ \\
\hline
\end{tabular}

Source: Authors' estimations.

Data were collected on the number of staff working at the ART clinic, how much time they spend there, how much time they work overall and staff salaries. Using a time motion approach and task checklist, staff roles and time spent on ART care were assessed. Salary costs are defined as fixed at facilities where there is a stand-alone ART clinic, since staff must work in the clinic however many patients attend. Salary costs at integrated clinics, where the antiretroviral treatment service jointly provided with other healthcare services, are defined as variable. Finally, the labor cost of the visit was calculated and estimated by multiplying the length of the visit by average salary of a particular cadre of worker per minute. The collected data was analyzed using the Statistical Package for the Social Sciences (SPSS) 16.0 and STATA 12 analysis software. All costs are presented in 2011 Ethiopian Birr (ETB) and United States dollar (USD). The analysis considers the collected data from the surveyed health facilities, considering the stratification of sampled health facilities. Following the hierarchical Ethiopia health tier system, health facilitates were categorized as hospitals or health centers, the health care professionals categorized as doctors or nurses/health offices, and types of activities as ART initiation or follow-up. The related evidence on the cost effectiveness of ART task shifting and patient satisfaction has been published elsewhere (Johns et al. 2014, Asfaw et al. 2014).

A paper by Johns et al. (2014) analyzed the cost and effectiveness difference between the maximal task shifting versus minimal task shifting, and concluded that sever drug reactions and ART drug regimens changes by the physician to the other clinical officers is not associated with a significant change in the treatment success rate or cost of the service. The second article analyzed the patient satisfaction with antiretroviral service and its implications for universal health coverage. The study showed high levels of patient satisfaction with the ART task shifting and recommends the inclusion of task shifting as a mechanism for scaling-up health services to achieve universal health coverage, particularly in the limited resource settings (Asfaw et al. 2014). Extending from the previous two studies (Johns et al. 2014, Asfaw et al. 2014) and considering the existing gap in the literature, this study aims to estimate the length of visit, cost of visit as well as to assess the relationship of the length of a visit and cost of visit, with the above listed explanatory variables. 


\section{Ethics Statement}

The study received scientific ethical review, follow-up and approval from the Scientific and Ethical Review Office (SERO) of the Ethiopian Public Health Institute. The research was also approved by the Institutional Review Board of Abt Associates Inc. Oral informed consent was received from all patients interviewed during the survey. The data was kept confidential through the course of the study and analyzed anonymously. The collected data was stored with both the Ethiopian Public Health Institute and Abt Associates Inc.

\section{Econometric Model}

A review of the literature shows that many factors are associated with ART treatment task shifting (Zachariah et al. 2009, Barbara and Kwadwo 2008, Monyatsi et al. 2013). Although many determinant variables contribute to ART task shifting success, this study has focused on the variation in the length of visit/cost of visit associated with decentralization from a physicianled, hospital-based program to the nurse/health officer-led health center delivery modality. The model assessed the association between the type of health professional (doctor, health officer or nurse), health facility (hospital or health center) and visit (initiation or follow-up) and the length and cost of a visit (Table 2).

The first (1) and second (2) models were constructed with the basic assumption of two separate models with similar, independent variables but different dependent variables in order to assess both the length and the cost of the visit. The functional form of the models is as follow:

$$
\begin{aligned}
& Y L_{i}=\alpha_{1}+\alpha_{2} D_{2 i}+\alpha_{3} D_{3 i}+\alpha_{4} D_{4 i}+U_{i} \ldots \ldots \ldots \ldots \ldots \ldots \ldots \ldots \ldots 1 \\
& Y C_{i}=\alpha_{1}+\alpha_{2} D_{2 i}+\alpha_{3} D_{3 i}+\alpha_{4} D_{4 i}+U_{i} \ldots \ldots \ldots \ldots \ldots \ldots \ldots \ldots 2
\end{aligned}
$$

where,

$\mathbf{Y} \mathbf{L}_{\mathbf{i}}=$ length of visit,

$\mathbf{Y C}_{\mathbf{i}}=$ cost of visit,

$\mathbf{D}_{\mathbf{2} \mathbf{i}}=$ is a set of dummy variables for the type of professional (doctors, nurses/health officers),

$\mathbf{D}_{\mathbf{3 i}}=$ is a set of dummy variables for the type of health facility (hospital, health center) and

$\mathbf{D}_{\mathbf{4 i}}=$ is a set of variables for type of visit (initiation, follow-up).

Following the definition by Gujarati (2002), the coefficients of dummy variables would give the median/mean value through comparing the dummy variables considered in the model estimation. According to the literature, the dependent variables (length of visit cost of visit) were required to have symmetrical distribution, low skewness and low kurtosis value (Gujarati 2002). 
Since most health economics data shows skewed outcome and high kurtosis and skewness values, we explore and apply the log transformation of the dependent variables.

Table 2. Detail Description of the Model Variables in the Econometric Model

\begin{tabular}{|c|c|c|c|}
\hline \multicolumn{4}{|c|}{ Dependent Variable for Model 1} \\
\hline Variables & Description & Data Type & Value \\
\hline $\begin{array}{l}\text { Log } \\
\text { Length of } \\
\text { visit }\end{array}$ & $\begin{array}{l}\text { Time spent with the } \\
\text { patient }\end{array}$ & $\begin{array}{l}\text { Continuous } \\
\text { variable }\end{array}$ & Minutes \\
\hline \multicolumn{4}{|c|}{ Dependent Variable for Model 2} \\
\hline $\begin{array}{l}\text { Log cost } \\
\text { per length } \\
\text { of visit }\end{array}$ & $\begin{array}{l}\text { Log transformation to } \\
\text { measure labor cost per } \\
\text { length of visit }\end{array}$ & $\begin{array}{l}\text { Continuous } \\
\text { variable }\end{array}$ & Minutes*Salary rate \\
\hline \multicolumn{4}{|c|}{ Independent Variables } \\
\hline $\begin{array}{l}\text { Facility } \\
\text { type }\end{array}$ & Type of facility for ART & $\begin{array}{l}\text { Dummy } \\
\text { variable }\end{array}$ & $\begin{array}{c}1=\text { Hospital, } 0=\text { Health } \\
\text { center }\end{array}$ \\
\hline \multirow{2}{*}{$\begin{array}{l}\text { Profession } \\
\text { al type }\end{array}$} & \multirow{2}{*}{$\begin{array}{l}\text { The professional at that } \\
\text { particular visit }\end{array}$} & \multirow{2}{*}{$\begin{array}{l}\text { Dummy } \\
\text { variable }\end{array}$} & $\begin{array}{c}1=\text { Nurse/Health officer, } \\
0=\text { Otherwise }\end{array}$ \\
\hline & & & $1=$ Doctor, $0=$ Otherwise \\
\hline $\begin{array}{l}\text { Type of } \\
\text { visit }\end{array}$ & Type of visit & $\begin{array}{l}\text { Dummy } \\
\text { variable }\end{array}$ & $\begin{array}{c}\text { 1=Continuing, } \\
0=\text { Initiation }\end{array}$ \\
\hline
\end{tabular}

Source: Authors' estimations.

As shown in Table 3, the transformed dependent variable (log of cost per length of visit) would result in low kurtosis (2.81) and skewness values (-0.04) compared with the non-transformed values of skewness (2.34) and kurtosis (15.1). Applying similar techniques, the transformed value of length of visit kurtosis decreased to (2.8) from (14.86), and the skeweness value decreased from $(2.35)$ to $(-0.41)$.

Table 3. Comparison of Log Transformation of the Dependent Variables

\begin{tabular}{|l|c|c|c|c|}
\hline & Cost of visit & $\begin{array}{c}\text { Log of cost } \\
\text { of visit }\end{array}$ & $\begin{array}{c}\text { Length of } \\
\text { visit }\end{array}$ & $\begin{array}{c}\text { Log of } \\
\text { visit }\end{array}$ \\
\hline Number of observations & 665 & 665 & 665 & 665 \\
\hline Mean & 1.72 & 0.35 & 8.42 & 1.95 \\
\hline Median & 1.42 & 0.35 & 7.00 & 1.94 \\
\hline SD & 1.14 & 0.61 & 5.67 & 0.61 \\
\hline Skewness & 2.34 & -0.04 & 2.35 & -0.41 \\
\hline Kurtosis & 15.1 & 2.81 & 14.86 & 2.80 \\
\hline
\end{tabular}

Source: Authors' estimations.

Considering the above factors, OLS regression was applied to the log transformed dependent variable to estimate the difference among health professional types, type of health facilities and the visit types. After transforming the dependent variable, the econometric equation to be estimated has the following functional form: 


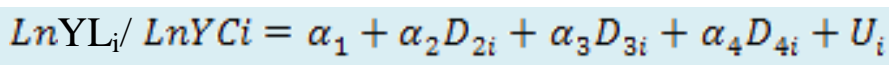

where,

$\operatorname{Ln} \mathbf{Y L}_{\mathbf{i}} / \operatorname{Ln} \mathbf{Y C}_{\mathbf{i}}=\log$ of cost per length of visit/log of length of visit,

$\mathbf{D}_{2 \mathbf{i}}=$ a set of dummy variables for the type of healthcare professional -1 if the professional is a nurse/health officer, 0 otherwise,

$\mathbf{D}_{\mathbf{3 i}}=$ a set of dummy variables for the type of health facility, and

$\mathbf{D}_{4 i}=$ is a set of variables for type of visit.

The detailed illustration of the models was explained in Table 2. Finally the log-transformed model was tested for multi-collinearity and heteroskedasticity using the Cook-Weisburg test (Halvorson and Palmquist 1980). The interpretation of the econometric models followed the approaches suggested by Halvorson and Palmquist (1980). According to these literature, the simielasticity for regressor with qualitative variables was analyzed by taking the antilog (to base e) of the estimated dummy coefficient, subtracting 1, and multiplying by 100 (Halvorson and Palmquist 1980).

\section{Results}

A total of 79 health facilities were covered during the survey. The number of patients interviewed from each health facility ranged from 10 to 15 . A total number of 665 patients interviewed for the time-motion studies to estimate the length of visit and cost per visit. The majority of patients $(77 \%)$ saw nurses, while $19.6 \%$ and $3.5 \%$ were treated by health officers and doctors, respectively. Sixty-two percent of the patients visited a health center, while the remainder attended a hospital. More than $60 \%$ of the patients examined were categorized as WHO stage I or II. The smallest proportion of patients (2.6\%) was WHO stage IV patients.

\section{Length of Visit and Cost of Visit}

The average time spent by patients receiving ART services at the hospital was 8.6 minutes, with a minimum of a minute to the maximum of 60 minutes per visit. While at the health center, the mean time spent was 8.3 minutes at the range of 1 to 38 minutes per visit. As depicted in Table 4, the median time spent with patients was almost similar at health centers (7.6 minutes) and at the hospitals (7 minutes), Applying the $t$-test and Wilcoxon rank-sum (MannWhitney) comparison test, there was no significance difference in the median time spent by the patients at the hospital and health centers. As shown in Table 4, the median and mean length of visit was also analyzed across the two health professional categories, i.e. physicians/doctors versus nurses and health officers. The mean length of visit by the patient with a doctor is 8.4 minutes $(\mathrm{SD} \pm 2.93)$, while with the other health care professions is 8.9 minutes $(\mathrm{SD} \pm 5.17)$. 
Table 4. The Length of the Visit (by the Minutes) Among the Surveyed Health Facilities

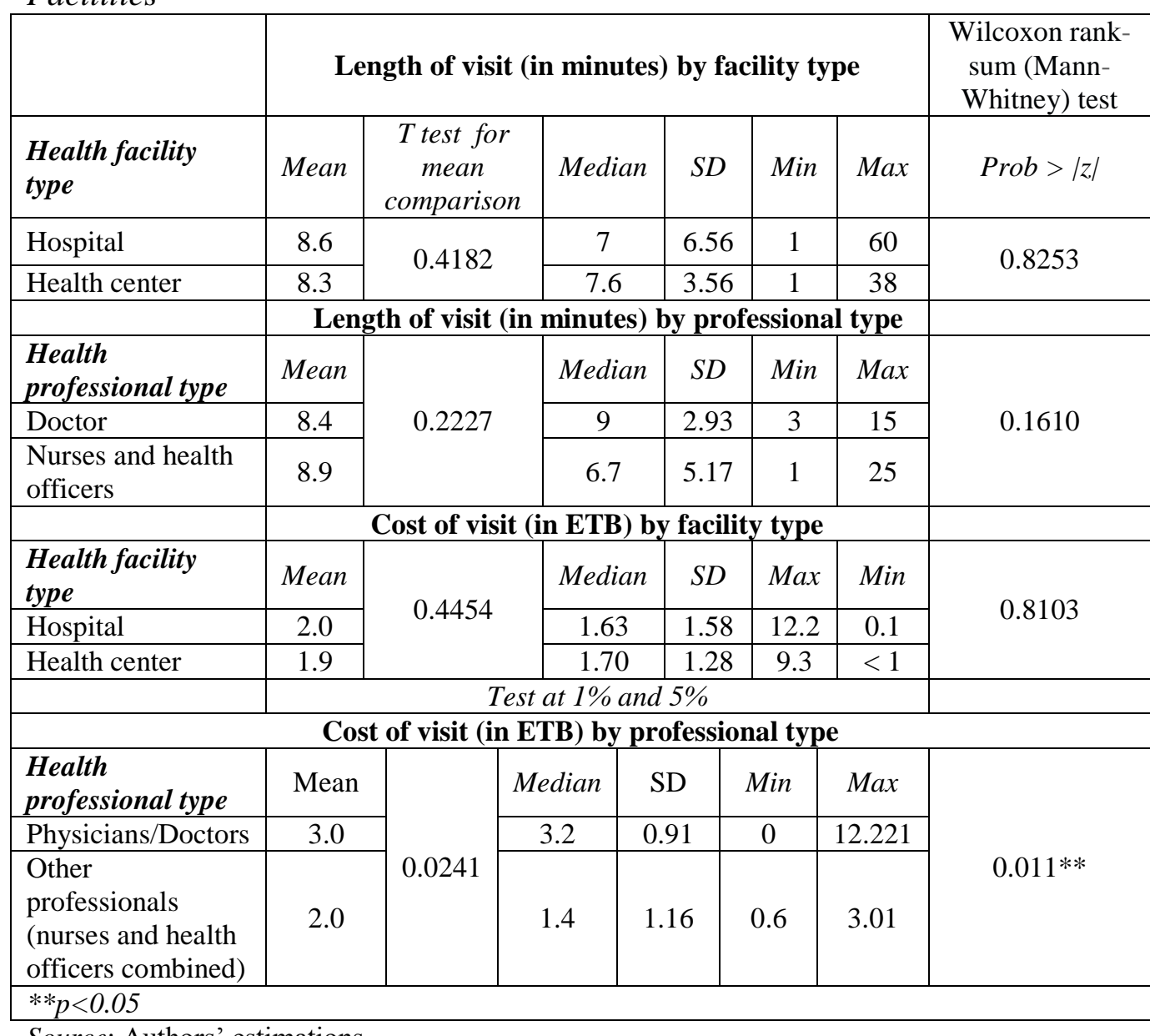

The overall mean cost per visit was 2 ETB, with a minimum of less than 1 birr and maximum of $12 \mathrm{ETB}$, which is equivalent with 0.71 USD considering the 2011 weighted average exchange rate $(1 \mathrm{USD}=16.9763$ ETB from Oanda website $\left.^{1}\right)$. This variation could be attributed to two factors: the amount of government employed healthcare professionals salary paid and the amount of time spent during the visit. As shown in Table 5, the highest visit cost was recorded when a patient visited a physician/doctor (3.02 ETB), while visits with a nurse had the lowest cost (1.90 ETB) at a statistical significance of $\mathrm{p}<0.05$. Health officers and nurses had similar costs per visit.

The labor cost per visit further varies with the type of the services provided: initiation, follow-up and referral. The highest unit cost was estimated for patients on initiation (2.32 ETB), and the lowest was for patients with continuing/follow-up visits $(1.95 \mathrm{ETB})(\mathrm{p}<0.05)$. The cost of a visit at hospitals averaged $2.04 \mathrm{ETB}$, which is slightly higher than the average cost at health centers $(1.91$ birr $)(\mathrm{p}<0.01)$.

\footnotetext{
${ }^{1}$ Weighted average exchange rate. Retrieved from http://goo.gl/CygoJU. [Accessed: 27 June 2015]
} 
Table 5. Cost of Visit Spent by Different Healthcare Professional Categories

\begin{tabular}{|l|c|c|c|}
\hline \multicolumn{4}{|c|}{ Cost of visit by professional type } \\
\hline $\begin{array}{l}\text { Health professional } \\
\text { Type }\end{array}$ & Mean & SD & Median \\
\hline Doctor & 3.0 & 0.91 & $3.2^{* *}$ \\
\hline Health Officer & 2.0 & 1.54 & $1.4^{* *}$ \\
\hline Nurses & 1.9 & 1.36 & 1.9 \\
\hline Total & 1.96 & 1.39 & 1.7 \\
\hline$* * p<0.01$ & \multicolumn{4}{|l|}{} \\
\hline
\end{tabular}

Source: Authors' estimations.

\section{Econometric Results}

A summary of the OLS model results for the dependent variable labor cost per visit is provided in Table 6 . The goodness of fit $\left(\mathrm{R}^{2}\right)$ for the model was found to be 0.02 , showing that the model explains little of the variation in the cost per visit. Even though $\mathrm{R}^{2}$ is low, the econometric model had low F-value which indicates strong statistical predictive power to explain the cost per visit variation. As show in Figure 1, the insignificant result from the CookWeisburg test indicates no heteroskadasticy. In addition, as shown in Table 6, test for multicollinearity was also performed, and no multicollinearity reported among the listed model variables.

The second model was estimated using the log of the length of visit as the dependent variable. As shown in Table 6, the coefficients of the second model are similar to the first model on the labor cost per visit. This clearly suggests that much of the difference in the cost per visit is due to the length of the visit. The test summary for multicollinearity and Cook-Weisburg test were presented in Figure 1 and Table 6 respectively.

Figure 1. Cook-Weisberg Test for Heteroskedasticity for Log Length of Visit

\begin{tabular}{|c|c|}
\hline $\begin{array}{l}\text { Ho: } \\
\text { Variables: } \\
\text { chi }^{2}(1): \\
\text { Prob>chi }\end{array}$ & $\begin{array}{l}\text { Constant variance } \\
\text { resid } \\
0.23 \\
0.6351\end{array}$ \\
\hline
\end{tabular}

Source: Authors' estimations.

Applying the Halvorson and Palmquist interpretation (1980), the model results indicate that the median length of visit for doctors is $16 \%$ higher than that of nurses and health officers when controlling for health facility type and type of visit (p-value $<0.05$ ). As shown in Table 6, the first model also shows that the median cost per visit for doctors is $15 \%$ longer than that of nurses and health officers ( $p$-value $<0.05$ ). Moreover, similar results were obtained for both the length of the visit and cost of visit dependent variables. The same analysis shows that the median cost per visit to hospitals was 1 percent higher than to health centers ( $p$-value>0.05). The analysis indicates that the length of visit for a follow up/continuing visit $(\mathrm{D}=1)$ would be $1 \%$ lower than that of an initiation visit ( $p$-value>0.05). 
Table 6. Summary Result of Modeling Log of Cost Per Visit and Log of Length of Visit

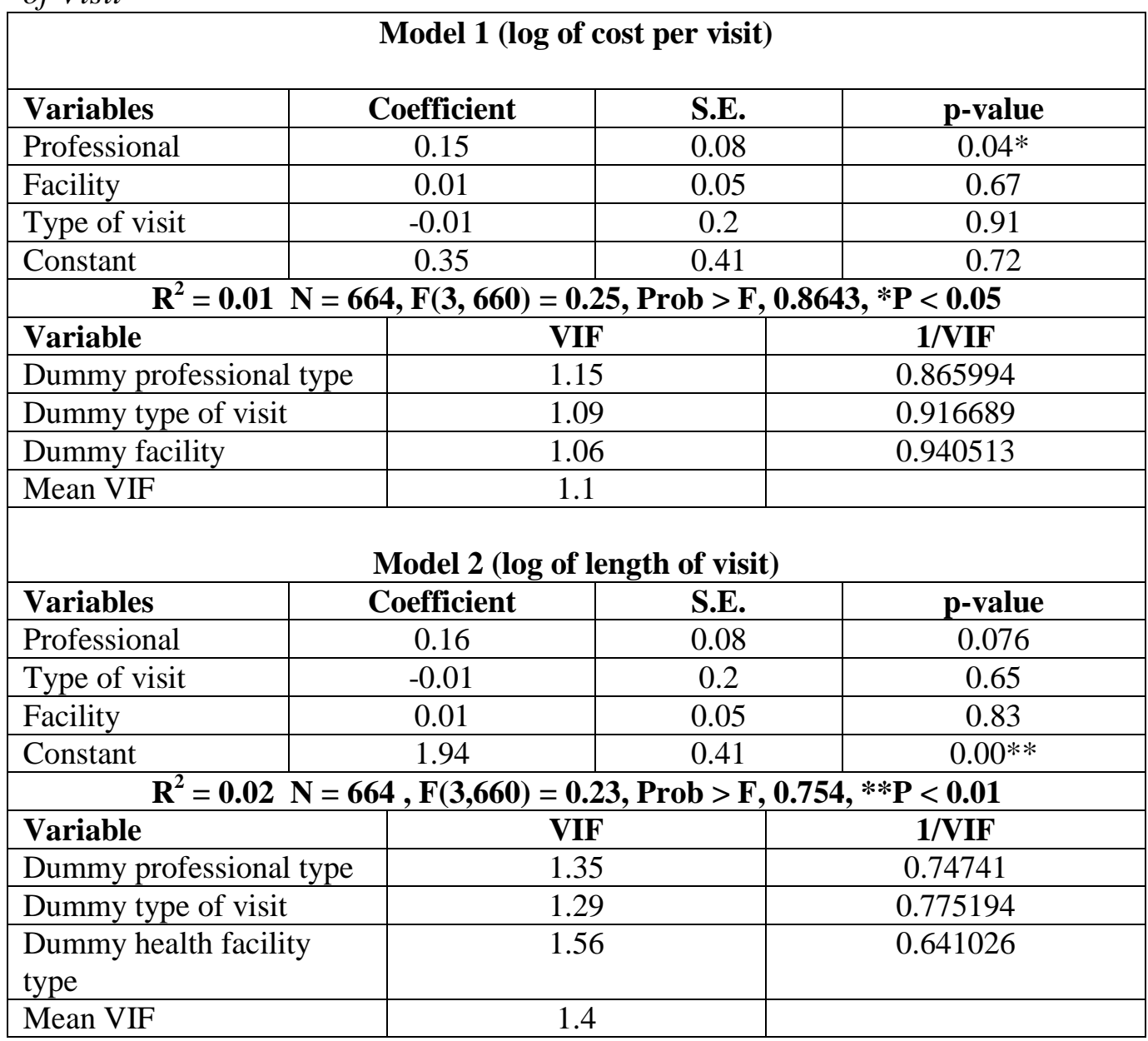

Source: Authors' estimations.

According to the analysis, there is no statistical difference detected between initiation and follow-up/continuing, this would probably attributed to the lower labor cost per visit and almost similar time spent by the patient visit on initiation or follow-up visit. In addition, similar antiretroviral service protocol is followed for the patient treatment both at the hospital and health center, which would probably, explains the reason for having no statistical significance between the median cost per visit at the hospital and medical cost of visit at the health center. The national salary grade/pay for the general practitioner doctors is almost similar with that of the health officers and senior nurses. This would support the insignificant result obtained between the dependent variable with the health facility type and type of visits. However, this finding will generally highlight a future research area to be investigated.

As per the OLS model results, there are no significance differences observed in the length of a visit to hospitals with a health center and follow-up versus continuing visit ( $\mathrm{p}$-value>0.05). This could possible attribute with a similar amount of time spent by the patient at the hospital and health center, as well as the type of visits (initiation versus follow-up of the treatment). More likely, the length 
of visit would probably be explained by other determinant factors which were not considered in our econometric model, for instance length of waiting time, technical efficiency, health care service acceptability, medical logistics and equipment availability. And these would also indicate a potential research area to be addressed in the future. However, to test the validity and robustness, the econometric models were tested for proper functional form, outliers, residual normality, homoskedasticity, multicollinearity, and found to be well-fit, which adds credibility to the findings (Figures 2, 3, 4a, 4b and 5).

Figure 2. Power Transformation for Cost Per Length of Visit

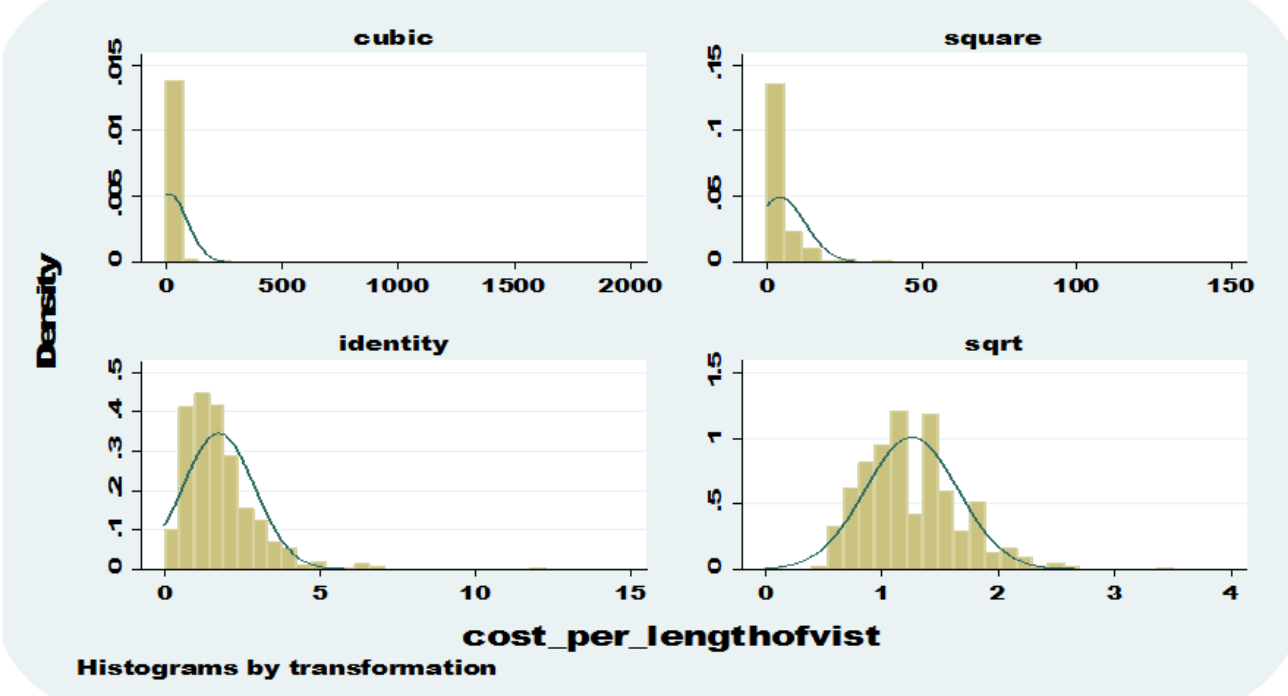

Source: Authors' estimations.

Figure 3. Power Transformation for Length of Visit

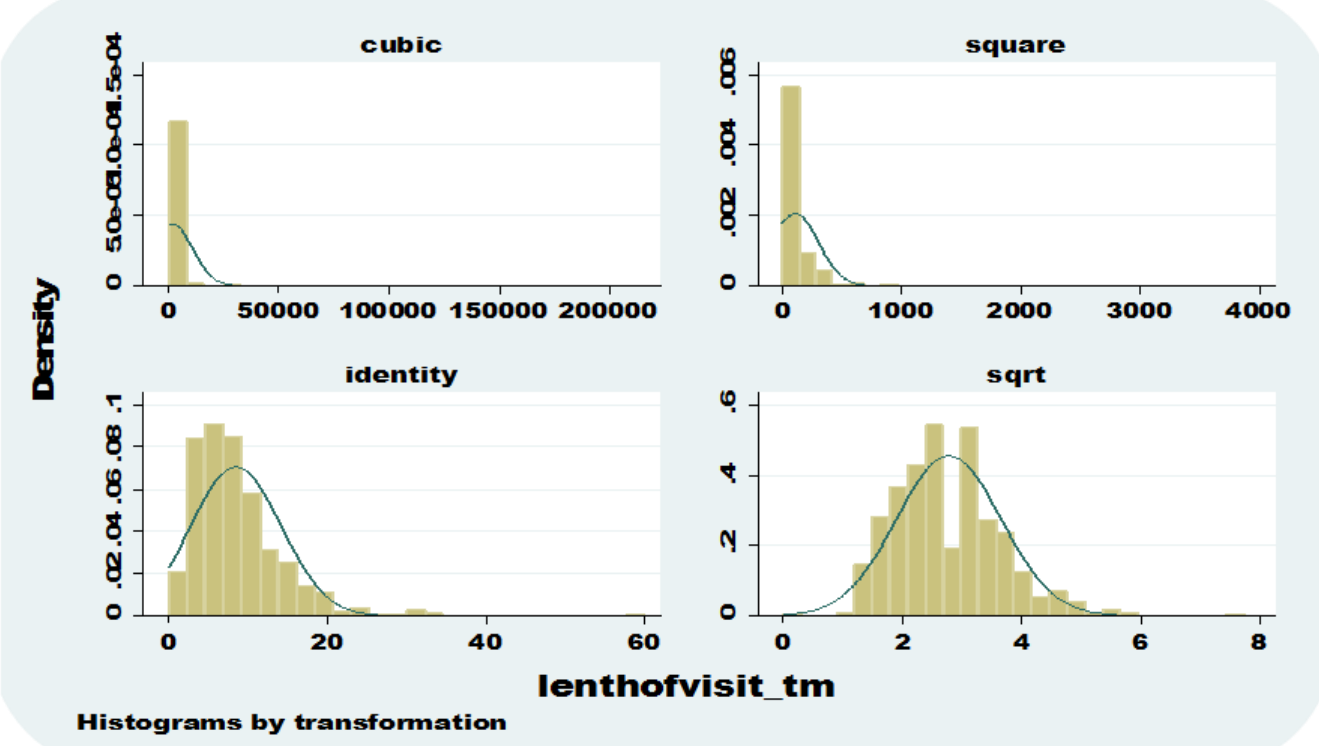

Source: Authors' estimations. 
Figure 4a. Testing the Normality of the Residuals, Cost Per Length of Visit

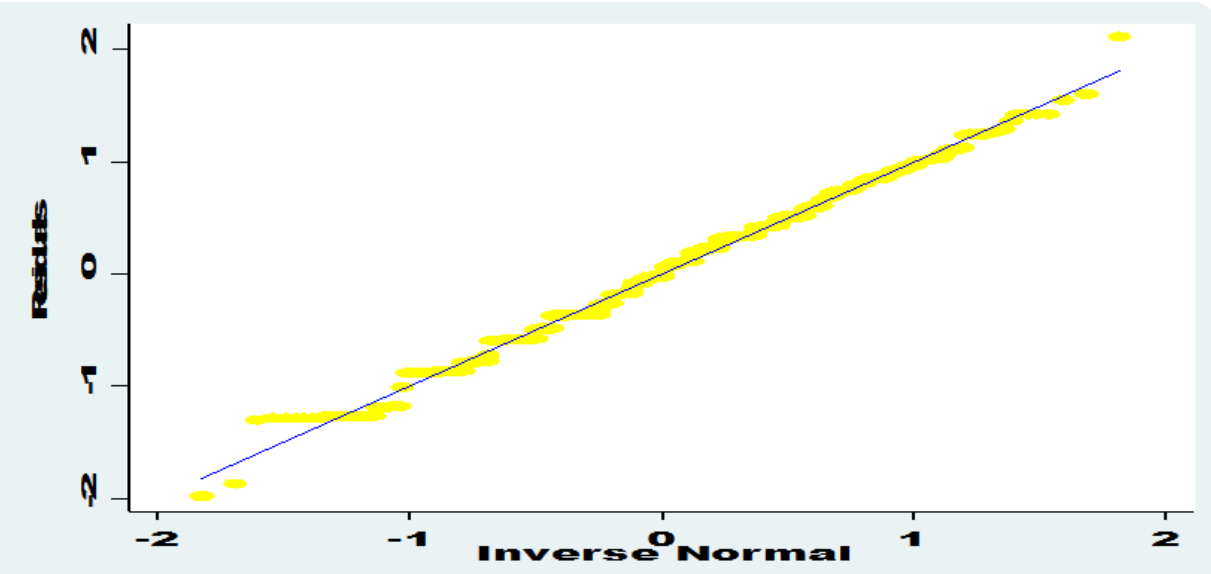

Source: Authors' estimations.

Figure 4b. Testing the Normality of the Residuals, Length of Visit

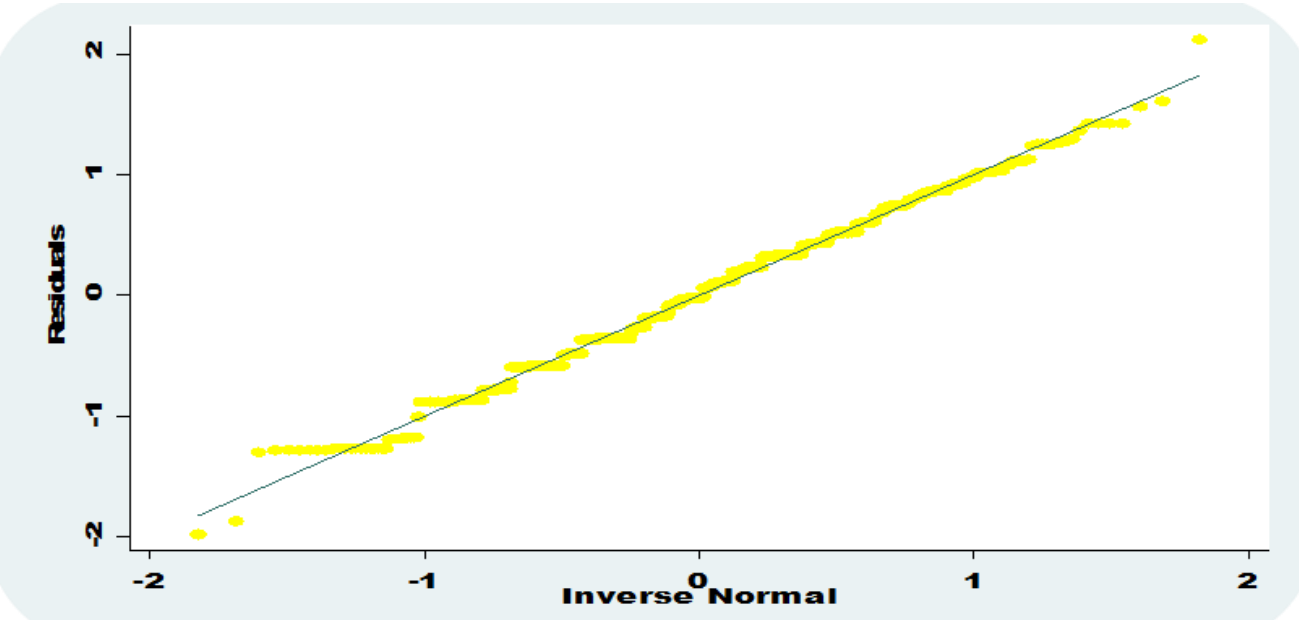

Source: Authors' estimations.

Figure 5. Multicollinearity Test Using Graph for Length of Visit

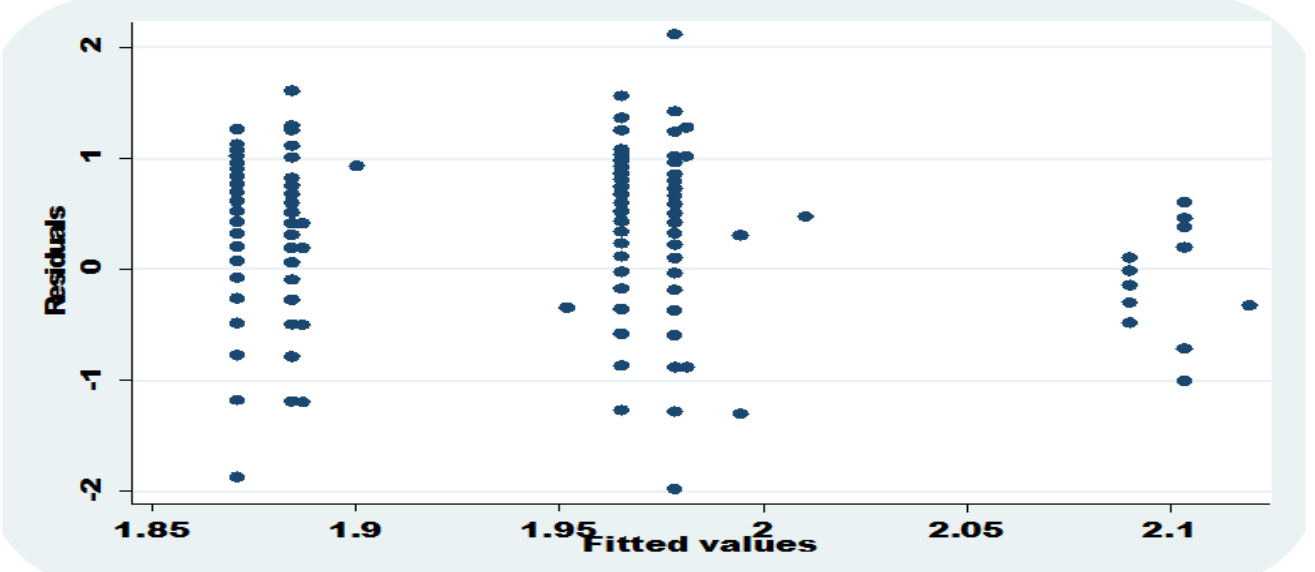

Source: Authors' estimations. 


\section{Discussion}

The study found a $15 \%$ lower cost of visit and $16 \%$ lower length of visit for ART patients treated by nurses and health officers, as compared with the physicians. The findings from the econometric model support the recent debate on task shifting (Zachariah et al. 2009, O'Malley et al. 2014, Edge 2008) health care delivery to the least costly health worker and who is capable of reliably performing this task. This micro-economic analysis strengthens recent findings on antiretroviral task-shifting in Namibia and Botswana which highlighted the relevance of task shifting in improving access, service quality and skills enhancement (O'Malley et al. 2014, Monyatsi et al. 2013).

The finding of the study also support the recent momentum in initiation of task shifting by the WHO (2008). Unlike the variable of the type of health professional, no statistically significant difference was detected in the effect of the type of health facility (hospitals or health centers) and type of patient examined (initiation or follow-up) on the length of visit and cost per visit. This suggests that efficiency gains are due to task shifting and not to either decentralization or different types of patients being sorted to different service providers. Furthermore, task-shifting was considered a cost-effective measure to maximize output (Babigumira et al. 2009, Buttorff et al. 2012), but cost saving should not be achieved at the expense of the quality of service provision. The health economics literature has also cautioned that the economic benefits generated by any intervention should not compromise the quality of care (Zachariah et al. 2009). However, a government report draws attention to the fact that services provided through a task-shifting approach are not necessarily inferior to a physician-led, team-based approach to providing ART services, provided necessary measures are taken assure quality (FMOH 2007).

Due to the dearth of evidence on the health facilities, the model focused and analyzed the statistically different relationship between length of visit and cost per length of visit using only three variables, such as: the level of healthcare service providing professional, type of health facility and type of patient examined. Further in-depth research that considers other determinant variables, such as the quality of care and the type of training for healthcare providers should be conducted in order to determine their impact on the overall cost difference. In addition, the insignificant results on the length of visit and cost of visit on the health facility type and type of visit will indicate future research topic. In general, the impact of ART task shifting on the broader public health domain is also an important topic for future research in limited resource setting countries like Ethiopia.

The limited availability of data constrained this study in capturing other determining factors in the model. The models were limited to supply-side independent variables, without considering other variables such as patients' socio-demographic characteristics, health seeking behavior, training, distance from the health facility and treatment success indicators, which are also likely to affect the length of visit and cost per visit. The overall ART task shifting holds the basic assumption on the similarity of service provision between 
professional trained nurses and the physicians. The detail model analysis follows this basic assumption. The validation of this assumption also needs further study. Moreover, the length of visit assessment has reported high length of visit range from a minute to an hour, and length of visit across the different types of healthcare professionals. More likely, the wider length of visit difference could be explained by the patients' status/condition. Patients with lower CD4 count and drug reaction will probably demands for relatively high amount of time for investigation, while the others in good health status and better CD4 status will demand a short length of visit, such as for drug refilling and short check-up.

The cost analysis captured only the labor visit cost, without considering other types of variable and fixed costs, such as medical supplies, equipment, training and infrastructure costs. The inclusion of these variables in the cost estimation and model analysis will probably result in to a different conclusion and recommendations. Despite this constraint and highlighted gaps, we believe that, this is the first attempt to estimate the cost of visit, length of visit and finally to analyze the economic significance of ART task shifting through applying a micro-econometric modeling tool in the context of limited resource setting country.

\section{Conclusions}

The length of visits for ART patients varied little with the tier of the health facility (hospital and health center). However, the estimated labor cost of a visit (wage rate*time spent) was less at the surveyed public health facilities than at private facilities. This is possibly due to the fact that staffs at public health facilities in Ethiopia earn less than at private facilities (Asfaw et al. 2012) and that the former have far more ART patients which could probably lead to lower unit cost per visit. Considering the limited resource setting at public health facilities in Ethiopia, this study highlighted a significantly lower length of visit and labor cost of a visit to nurses and health officers. According to the econometric model analysis, in Ethiopia, task-shifting to less specialized health-care workers yields additional economic benefits and advantage. This will have an important healthcare policy implication on the expansion of ART task-shifting. Understanding its economic significance and the current movement towards Universal Health Coverage, task shifting in general and ART task shifting in particular should be a priority focus area by the Federal Ministry of Health and concerned stakeholders in the health sector. On the other hand, appreciating the economic relevance of task shifting in the limited resource countries, health sector policy makers should not undermine patients' benefits and public health outcomes in general, and further supplementary research is also recommended to substantiate the current finding on the economic significance of task shifting. 


\section{Acknowledgments}

Girma Debela and Abiy Tsegaye led data collection teams and contributed to the design of the data collection tools. Kimberly Kennedy (Abt Associates) helped train and oversee data collectors. The Federal Ministry of Health (FMOH) Human Resource Development and Administrative Directorate, Ethiopia, Federal HIV/AIDS Prevention and Control Office (FHAPCO), Addis Ababa City Administration Health Bureau, Amhara Regional Health Bureau, Oromiya Regional Health Bureau and the Benishangul Gumuz Regional Health Bureau all facilitated data collection and contributed to the concept of the study. Management Sciences for Health, International Training and Education Center for Health, ICAP and Johns Hopkins University generously provided us with their time, thoughts, and cost data. Nejmudin Bilal, Itamar Katz and Hailu Zelelew contributed to the conceptual design of the study. USAID/Ethiopia also contributed their thoughts and time to make this study possible. The authors are grateful for their help and support. The views expressed in this article are those of the authors and do not necessarily reflect the official policy or position of the US Government.

\section{References}

Asfaw E, Tushune K, Abdosh B, M Chrispim PP (2012) Cost Effectiveness Analysis of PMTCT Service Delivery Modalities in Addis Ababa (Using Decision Models). Internation AIDS Economics Network (iAEN). Retrieved from http://www.iaen. org/library/Presentation_1_Elias_Asfaw.pdf. [Accessed: 03 June 2015]

Asfaw E, Dominis S, Palen JG, Wong W, Bekele A, Kebede A, Johns B (2014) Patient satisfaction with task shifting of antiretroviral services in Ethiopia: implications for universal health coverage. Health Policy and Planning 29(Suppl. 2): ii50-ii58.

Barbara MP, Kwadwo M (2008) Task shifting in healthcare in resource-poor countries. The Lancet 372: 870-871.

Babigumira JB, Castelnuovo B, Lamorde M, Kambugu A, Stergachis A, Al E (2009) Potential impact of task-shifting on costs of antiretroviral therapy and physician supply in Uganda. BMC Health Services Research 9: 192-198.

Buttorff C, Hock RS, Weiss, HA, Naik S, Araya R, Kirkwood BR, Chisholm D, Patel V (2012) Economic evaluation of a task-shifting intervention for common mental disorders in India. Bulletin of World Health Organization 90: 813-821.

Charles FG, Siobhan C, René E, Sandy G, Jos P, Al E (2006) The WHO public-health approach to antiretroviral treatment against HIV in resource-limited settings. The Lancet 368: 505-510.

Edge L (2008) Task shifting may prove key to tackling infectious diseases. The Lancet Infectious Diseases 8(2): 81.

FMOH (2007), Accelerating Access to HIV/AIDS Treatment in Ethiopia: Road Map 2007-2008/10. HIV/AIDS Prevention and Control Office. Addis Ababa, Ethiopia: Ministry of Health of the Government of Ethiopia. 
Gessessew A, Barnabas GA, Prata N, Weidert K (2011) Task shifting and sharing in Tigray, Ethiopia to achieve comprehensive emergency obstetric care. International Journal of Gynecology and Obstetrics 113: 28-31.

Gujarati DN (2002) Basic Econometrics, $4^{\text {th }}$ edition. McGraw-Hill/Irwin.

Halvorson R, Palmquist R (1980) The interpretation of dummy variables in semilogarithmic equations. The American Economic Review 70: 474-475.

Harries A, Schouten E, Libamba E (2006) Scaling up antiretroviral treatment in resource-poor settings. Lancet 367: 1870-1872.

Johns B, Asfaw E, Wong W, Bekele A, Minior T, Kebede A, Palen J (2014) Assessing the costs and effects of antiretroviral therapy task shifting from physicians to other health professionals in Ethiopia. JAIDS Journal of Acquired Immune Deficiency Syndromes 65(4): e140-e147.

Kinfu Y, Dal Poz MR, Mercerb H, B Evans D (2009), The health worker shortage in Africa: are enough physicians and nurses being trained? Bulletin of World Health Organization 87: 225-230.

Monyatsi G, Mullan PC, Phelps BR, Tolle MA, Machine EM, Gennari FF, Makosky J, Anabwani GM (2013) HIV management by nurse prescribers compared with doctors at a paediatric centre in Gaborone Botswana. South African Medical Journal 102(1): 34-37.

O'Malley G, Asrat L, Sharma A, Hamunime N, Stephanus Y, Brandt L, Ali D, Kaindjee-Tjituka F, Natanael S, Gweshe J, Feldacker C, Shihepo E (2014) Nurse Task shifting for antiretroviral treatment services in namibia: implementation research to move evidence into action. PLoS ONE 9(3): e92014.

WHO (2007) HIV/AIDS Programme Strengthening Health Services to Fight HIV/AIDS. Task Shifting to Tackle Health Worker Shortages. Retrieved from http://www.who.int/healthsystems/task_shifting_booklet.pdf. [Accessed: 15 May 2015].

WHO (2008) Task Shifting Global Recommendations and Guidelines: Treat, Train, Retain. Geneva, Switzerland: World Health Organization.

UNAIDS (2013) Global Report: UNAIDS Report on the Global AIDS Epidemic 2013. Joint United Nations Programme on HIV/AIDS. Switzerland: United Nations Programme on HIV and AIDS.

Zachariah R, Ford N, Philips M, Lynch S, Massaquoi M, Janssens V, Harries AD (2009) Task shifting in HIV/AIDS: opportunties, challenges and proposed actions for sub-Saharran Africa countries. Transaction of the Royal Society of Tropical Medicine and Hygiene 103(6): 549-558. 